\title{
New developments at the Flood Forecasting Centre: operations and flood risk guidance
}

\author{
C. Pilling \\ Flood Forecasting Centre, UK
}

\begin{abstract}
The Flood Forecasting Centre (FFC) is a partnership between the UK Met Office and the Environment Agency, established in 2009, to provide an overview of flood risk across England and Wales. Based at the Met Office in Exeter, the FFC provides flood guidance services covering England and Wales, primarily for the emergency response community.

The FFC provides forecasts for all natural sources of flooding, these being fluvial, surface water, coastal and groundwater. This involves an assessment of possible hydrometeorological events in the next five days as well as their likely impacts. In addition, during times of heightened flood risk, close communication between the FFC and the Environment Agency allows mobilization and deployment of staff and flood defences at longer lead times. This mobilization is becoming increasingly important and high profile within Government.

This paper considers new developments in forecasting fluvial, surface water and coastal flood risk. This includes: (1) implementing Met Office deterministic and ensemble high-resolution numerical weather prediction data feeds to drive the distributed hydrological model, Grid-to-Grid (G2G); (2) a prototype for surface water hazard impact model; and (3) improvements in coastal flood forecasting. However, challenges remain, for example, improving forecasting at short lead times through improved nowcasting, also longer lead time forecasting beyond day 5, and integrated system modelling to, for example, capture the complex interactions between fluvial and coastal flooding.

Keywords: flood forecasting, risk based, joined up communication, emergency response.
\end{abstract}




\section{Introduction}

The Flood Forecasting Centre (FFC) is a partnership between the UK Met Office, the Environment Agency (EA) and National Resource Wales (NRW), which provides flood risk forecasts for England and Wales. After the summer flooding of 2007 in the UK when 55,000 properties flooded, 13 lives were lost, 7,000 people were rescued and there were $£ 4.5$ billion damages, the UK Government commissioned the Pitt Review [1]. This identified a need to join up the hydrological and meteorological expertise of the Environment Agency and Met Office, so the combined information would help emergency responders understand potential flood risk better. From a flood forecasting perspective, two of the key recommendations from the Pitt Review were:

- 'The Environment Agency and the Met Office should work together, through a joint centre to improve their technical capability to forecast, model and warn against all sources of flooding (Recommendation 6).

- 'The Met Office and the Environment Agency should issue warnings against a lower threshold of probability to increase preparation lead times for emergency responders' (Recommendation 34).

These recommendations resulted in the establishment of the FFC with staff brought together staff from their parent organisations to a single physical location. Subsequently, the Flood and Water Management Act 2010 introduced legislation to address the threat of flooding from different sources, highlighting the risk-based approach, and the arrangements for forecasting and warning across England and Wales.

The FFC is responsible for issuing longer lead time guidance to the emergency response community, which include the fire and rescue services and lead local flood authorities, to enable a proportionate and risk-based response.

\section{Flood risk assessment and communication}

Emergency responders, or Category 1 and 2 responders, as defined by the Civil Contingencies Act, receive flood guidance from the FFC. Within the centre, the team of operational hydrometeorologists are responsible for making the national assessment of likely impacts and flood risk through highly effective communication links established between the meteorological, hydrological and responder communities. This national assessment for all sources of flooding is communicated at least once a day, covering a 5-day period, though the Flood Guidance Statement (FGS, fig. 1). The FFC's collaborative process for assessing flood risk is underpinned by the flood risk matrix (shown in fig. 2). The flood riskbased approach adopted by the FFC is shared with the UK National Severe Weather Warning Service and during flood events the two services align in order to achieve maximum reach, effectiveness and authority. Recent developments and future challenges of the national flood risk assessment are now considered. 


\section{FLOODFORECASTINGCENTRE}

a working partnership between 8 Finvircermen

\section{Flood Guidance Statement 10:30hrs Friday 14 February 2014}

Our assessment of daily flood risk for England and Wales, working with flood forecasting teams in the Environment Agency and Natural Resources Wales, is below.

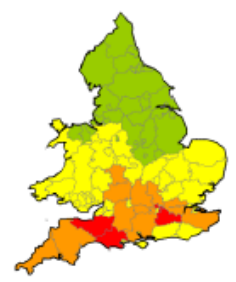

10:30 - 23:59hrs Friday

14 February 2014

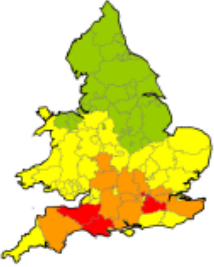

Saturday 15 February 2014

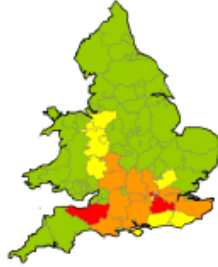

Sunday 16 February 2014

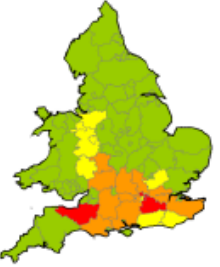

Monday 17 February 2014

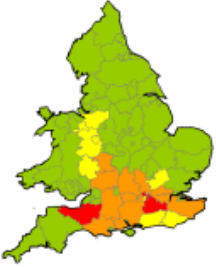

Tuesday 18 February 2014

HIGH flood risk for Dorset for coastal flooding today (Friday) and into Saturday. HIGH flood risk along the River Thames in Windsor \& Maidenhead and Surrey for the next five days. HIGH flood risk for Somerset Levels.

Figure 1: $\quad$ Flood Guidance Statement - extract from 10:30 issue 14 Feb 2014.

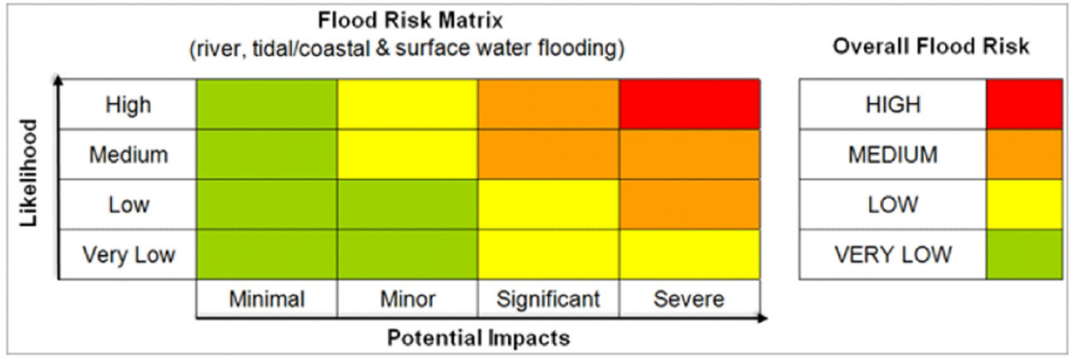

Figure 2: The flood risk matrix.

\section{Countrywide flood forecasting}

Flood forecasting across England and Wales is delivered at both a national and a local level, with these services complementing each other to support the delivery of consistent flood guidance and flood warning. This paper focuses on the developments in countrywide flood forecasting modelling approaches delivered at the national level. 


\subsection{Review of countywide flood forecasting approaches}

This section provides an overview of operational flood forecasting, and how the national flood forecasting models adopted by the FFC relate to recent research. Future challenges and research priorities identified by national approaches, and how these relate to science and future research in flood forecasting, are outlined in Section 4.

Different models and configurations have been adopted by different National Meteorological and Hydrological Services (NMHS), with a useful summary provided by Adams and Pagano [2]. Typical approaches for operational flood forecasting at the National and Regional scales involve numerical weather prediction data being used to drive semi-distributed or gridded hydrological models. Indeed, this is the approach adopted by the FFC, as well as by the European Flood Awareness System (EFAS; Roo et al. [3]) and the Global Flood Awareness System (GloFAS; Alfieri et al. [4]).

Price et al. [5] provide a useful summary of the relevant literature on operational flood forecasting, outlining the Lisflood hydrological model used in EFAS and also directs the reader to the distributed model intercomparison project (DMIP; Smith et al. [6]). The approach adopted by the FFC, as described below, is unique given the high spatial and temporal resolutions, and that it provides a forecast for all catchments in England and Wales out to 6 days. Future model improvements are likely to be realised from refinements to land surface modelling schemes such as the Joint UK Land Environment Simulator (JULES; Best et al. [7]) and high resolution, fully coupled ocean-atmosphere-land surface operational models. Recent research that is likely to benefit operational flood forecasting is considered in Section 4.

\subsection{Countywide fluvial flood forecasting}

The Grid-to-Grid (G2G) model uses a simple runoff production scheme to generate surface and sub-surface runoff from inputs of gridded rainfall and potential evapotranspiration, as shown in fig 3 . Runoff production is controlled by the soil characteristics of each $1 \mathrm{~km} \times 1 \mathrm{~km}$ grid cell, and these are defined from spatial data sets covering soil/geology and land cover properties. As described by Moore [8], the variation in water holding capacity within grid squares is represented in a probability distributed way. The $\mathrm{G} 2 \mathrm{G}$ offers a number of advantages over other modelling configurations which make it suitable for large scale, countrywide application; for example, see Cole and Moore [9] and Price et al. [5]. The key benefits are this national approach are summarised in Table 1.

Results from the G2G model are not generally expected to be as good those produced by locally calibrated models. There are two main reasons for this. First, G2G is broadly calibrated across England and Wales with fewer parameters than most locally applied models (Environment Agency [10]), so there is less fine tuning to specific catchments. Second, G2G model also uses a simple routing scheme which is unable to accommodate complex channel/floodplain flow processes, structures and fluvial/tidal interactions. 


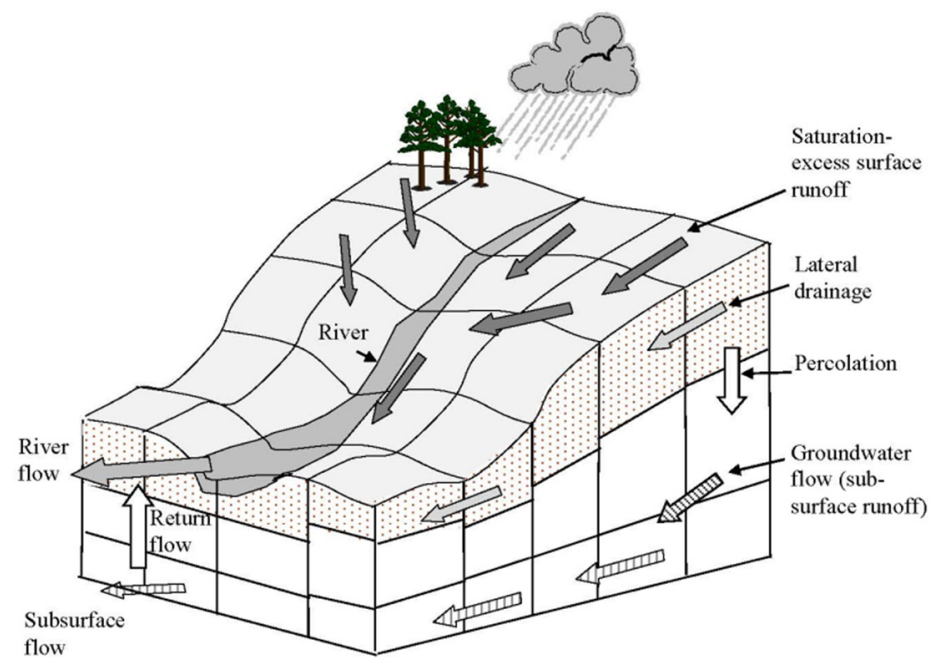

Figure 3: Schematic of the G2G model.

Table 1: $\quad$ Benefits of G2G for countrywide forecasting.

- The models distributed nature, at a fine spatial resolution allows for better representation of the spatial variation in rainfall input and catchment response.

- $\quad$ Forecasts for each grid cell, meaning that the model effectively forecasts 'everywhere'.

- The use of a small set of regional parameters, supported by pre-existing digital data sets for model configuration and parameterisation.

- A national calibration which allows for a manageable process undertaken at selected river gauge locations - this contrasts with calibration across all modelled catchments individually.

- It can be used to forecast for un-gauged locations, highlighting its potential usefulness for flood forecasting across all locations.

- The model is computationally efficient and fast to run for nationwide real-time flood forecasting on a $1 \mathrm{~km}^{2}$ model grid - this is especially important when running ensemble data sets.

In operational forecasting $\mathrm{G} 2 \mathrm{G}$ is run routinely using the latest UK Met Office high resolution deterministic and ensemble rainfall forecasts. The operational hydrometeorologist needs to be able to identify areas of particular risk from the wealth of forecast data available. Fundamental to forecasting flood risk at the FFC is the ability to make a link between fluvial flow and impact, where impact is measured in terms of flood damage to lives and livelihoods. Therefore, the FFC use visualisations of gridded probability of exceeding a flow of specified return period in order to identify the most likely areas at risk. 
A recent development in countrywide flood forecasting is the use of high resolution downscaled $\sim 2 \mathrm{~km}$ rainfall data feeds to drive $\mathrm{G} 2 \mathrm{G}$ at the national scale. The use of ensembles gives 'sight, or awareness' of more extreme scenarios, as well as a likelihood information as required in the matrix (fig. 2).

An initial analysis of these ensemble driving G2G for Cumbria 5-6 December 2015 (fig. 4) indicates that spatially it provided good guidance on those locations that were expected to see some of the largest responses, especially in north Cumbria and the South Tyne. However, the signal for large responses in some catchments, particularly through central, south Cumbria, River Wyre, Lune and west Cumbria rivers appeared too low. This event, along with three other through winter 2015-16, are being investigated further to refine the modelling.

This approach of generating river flow ensemble provides the FFC with a means of objectively assessing the range of variability in river flow forecasts through the 5-day FGS period. The FFC is now able to visualise the potential spatial variability of forecast river responses across the whole of England and Wales, to a range of plausible rainfall scenarios from a downscaled precipitation ensemble prediction system. This provides the FFC with a model-driven 'first assessment' for river flood risk across each county/unitary authority in England and Wales for the 5-day period of the FGS. This is a powerful approach which, when used in conjunction with existing national and catchment scale deterministic model forecast output and expert interpretation, provides a strong objective basis for our county scale fluvial flood risk guidance.

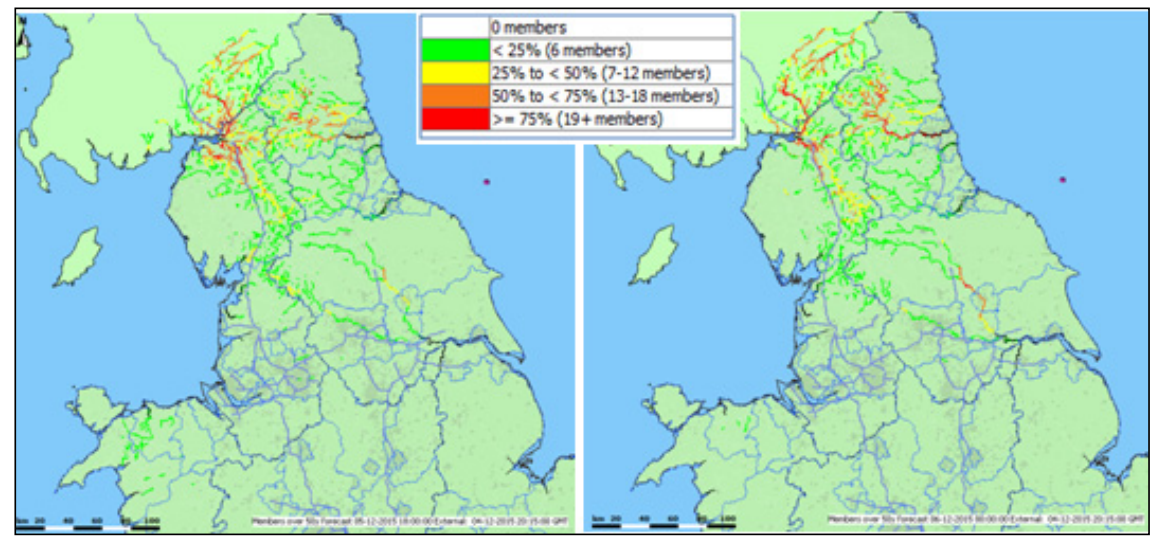

(a)

(b)

Figure 4: G2G, spatial gridded output using downscaled MOGREPS-G ensemble, showing members greater than 50 -year forecast for 5 th (a) and 6th (b) December 2015; based on 4th December model run. 


\subsection{Countrywide surface water flood forecasting}

The FFC incorporates an assessment of flood risk from surface water in the FGS. In 2010, the Surface Water Decision Support Tool (SWFDST: Halcrow [11]) was introduced into FFC operations. The tool imports data on the likelihood of exceeding a number of pre-defined return period rainfall events derived from each run of the high resolution ensemble model. It then calculates a flood-impact weighted score for all of the 109 county and unitary authorities across England and Wales, taking into account urbanisation and soil moisture status. The surface water flood impact assessment is therefore not based on storm intensity alone, but also takes into account the level of urbanisation in an area and the prevailing antecedent conditions.

The next step is to pilot a more dynamic, impact based capability through the Natural Hazards Partnership [12]. This Surface Water Hazard Impact Model described by Cole et al. [13] explains the benefits from using a surface water flood hazard footprint from Moore et al. [14] G2G computed for given rainfall events. This is used with reference to vulnerability and exposure datasets to define overall flood risk. An operational pilot is running in the FFC later this year.

\subsection{Countrywide coastal flood forecasting}

The FFC provides forecasts of overall coastal flood risk by working with Environment Agency forecasting centres. Short and medium range deterministic and surge data (as shown in fig. 5) for Newport, Wales, is used in combination with wind, wave data to build the flood risk assessment. Forecast wind data is as onshore winds can increase overtopping of coastal defences exacerbating the impacts of coastal flooding.

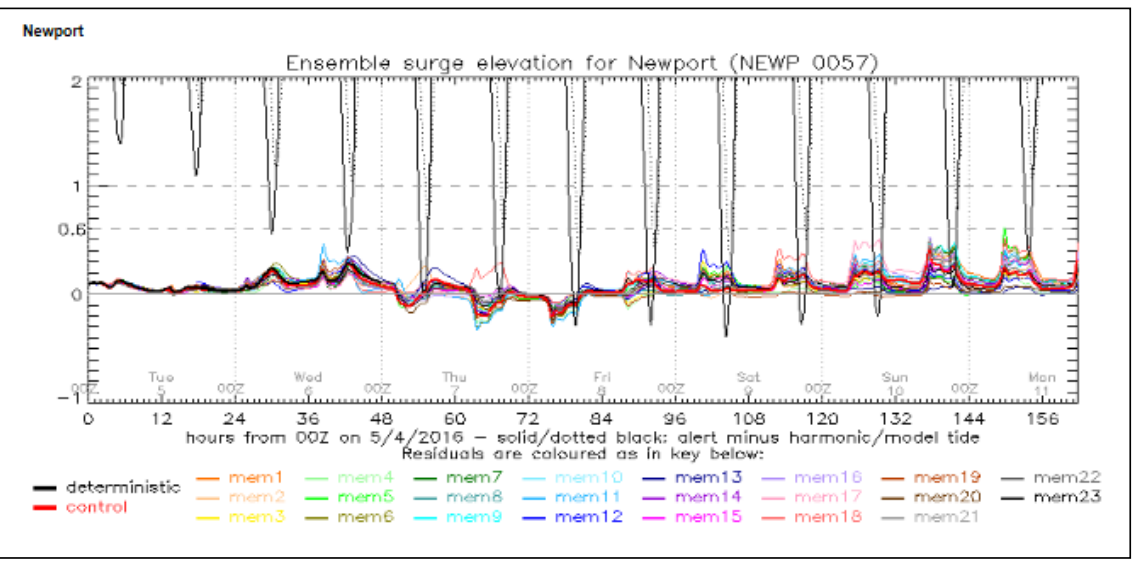

Figure 5: Surge ensemble output for Newport on the south coast of Wales, for the deterministic and the medium range ensemble forecasts. 
At lead times of 7 to 15 days, and indeed further ahead medium range ensemble weather forecasts from the European Centre for Medium-Range Weather Forecasts and the Met Office monthly and seasonal model, GLOSEA, are assessed to identify synoptic weather patterns that could lead to coastal flooding impacts. In the past, this longer range analysis was done subjectively by 'eye-balling' postage stamp displays of ensemble data to identify synoptic patterns that might lead to an increased coastal flood risk. This process has now been replaced by an objective measure derived from the Met Office's 'Decider' tool, configured to objectively identify the risk of a significant coastal flood event in the medium range period along the UK coastline.

The tool presents the probability of these high risk regimes affecting Britain and provides guidance of the risk of coastal flooding in the medium range period. Fig. 6 is an example of the output from the tool, based on the 00 GMT run of the ECMWF model on 5 April 2015.

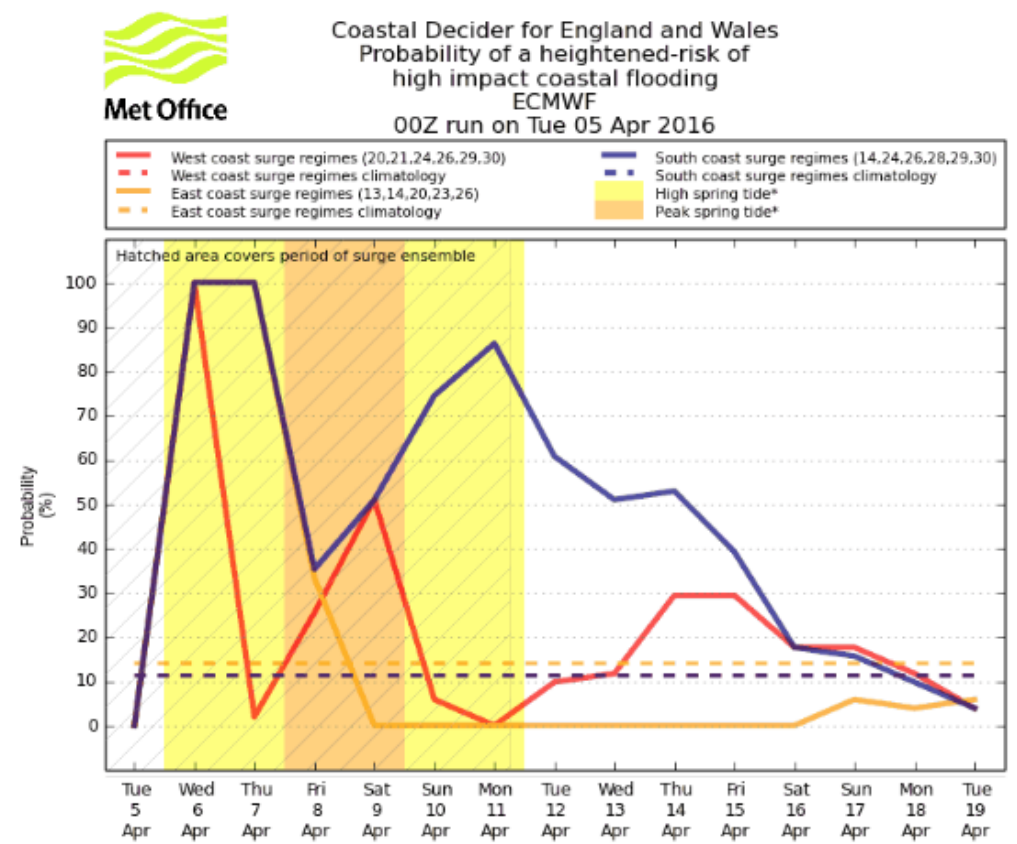

Figure 6: Example output from the Weather Regime Analysis tool. Plot shows some increased probability of coastal flooding associated regimes for the west, south and east coasts during the forecast period. Spring tide periods are highlighted in yellow, with the maximum highlighted in orange. 


\section{Future flood forecasting challenges}

With the FFC acting as a catalyst, working relationships between the Met Office, Environment Agency and Natural Resources Wales have flourished. This has resulted in a more efficient use of resources and the FFC has grown to become a trusted adviser in improving resilience and preparedness to flood hazards.

Flood forecasting in Britain has undergone a number of challenging tests in recent years (as summarised in table 2). These events have helped endorse the benefits from the improvements already implemented in our forecasting capability, and also to distil our challenges that are likely to result in step changes over the following decade. Improvements that are likely to lead to these step changes are summarised in table 3 .

Table 2: $\quad$ Summary of recent floods across England and Wales.

- $\quad$ November 2009: a slow moving weather front and orographically enhanced rainfall brought severe flooding to Cumbria, NW England - over 5,000 homes and businesses affected.

- $\quad$ Summer 2012: successive low pressure systems brought widespread flooding across England.

- Winter 2013-14: exceptional for the duration of flooding and was the wettest winter in the UK's observational records that extend back almost 250 years in England and Wales.

- Winter 2015-16: record breaking 24 hour and event rainfall totals with two periods of severe flooding.

Table 3: Areas to target for improvements.

- Nowcasting science: to forecast rapidly developing situations in near real time and flash flooding in urbanised areas and rapid response catchments.

- $\quad$ Estuaries and other high risk areas: coupling national river flow models with coastal and hydrodynamic estuary models.

- Longer range precipitation and fluvial ensembles: to forecast response in slower responding rivers.

- Enhanced longer range coastal ensembles: to develop and fully exploit the full potential of total water levels from surge and waves.

- Longer lead time projections: for all sources of flooding, including at greater lead times of up to 30 days.

- Concurrent flood risk: improved understanding of multiple sources and joint probabilities.

- Contextual information: understanding of severity of floods and attribution in a non-stationary climate.

- Multi hazard impact forecasting: improving forecasting, observation and reporting of flood impacts as well as the understanding of customer response triggers.

- Making science relevant: communicating science for example the risk matrix, drawing on social science. 


\subsection{Short lead times}

The most dangerous floods include those that result from rapidly developing convective systems, or the organisation or alignment of storm cells that may result in flash flooding over large urbanised areas or rapid response catchments such as Boscastle, as documented by Golding [15]. These are the most challenging to predict.

Improvements in real time observations, such as radar capability and improved orographic correction schemes will all translate into better estimates of rain rates and storm tracking. These improved observations, combined with more rapid and frequent data assimilation (e.g. hourly) enabled by more powerful high performance computer will translate into improvements in flash flooding tools and techniques.

\subsection{Longer lead times (day six to seasonal)}

During winter 2013-14, and again winter 2015-16 existing flood forecasting lead times were challenged with a desire for longer range information. Therefore, it is important to further develop and operationalise our understanding of global teleconnections. Scaife et al. [16] describes advances in seasonal weather forecasting are illustrating significant skill in predicting the North Atlantic Oscillation and temperature and precipitation forecasts over the UK at particular times of the year. These should be developed and refined into longer range flood risk forecasts.

\subsection{Integrated modelling and forecasting}

It is useful to consider concurrent river and coastal flooding. As Pilling et al. [17] describe, a typical scenario could be a protracted stormy period bringing successive intense low pressure systems across Britain. This could result in a storm surge coinciding with high tides and large waves being driven onshore concurrent with saturated river catchments and high flows and further heavy rainfall.

Improvements are likely to be offered through an integrated modelling framework that considers the optimal coupling of physical interactions between the atmosphere, waves, oceans, land surface and hydrology. Lewis et al. [18] describe such a system being explored under the UK Environmental Prediction prototype with the aim being to provide the best possible national environmental prediction system at a $1 \mathrm{~km}$ spatial resolution. This will provide optimum boundary conditions in higher resolution models, and a test bed for coupled environmental prediction across scales.

\subsection{People, skills, interpretation and engagement}

Finally, and most importantly, in order to realise the full operational benefits of scientific developments it is essential to continue to develop our people who can use, interpret and add value to what will be increasing amounts of information. 
This includes the advancement of hydrometeorology as a skill supported by vocational and professional training by PAA $\backslash$ VQSET [19].

\section{Summary and conclusions}

Strong working relationships and a truly collaborative approach are fundamental in making key operational decisions effectively and efficiently from all sources of flooding. Furthermore, close working with emergency responders and Government is essential to optimise all-round performance in an event - when it really matters. The end-to-end flood warning service is optimised by 'blending' the national forecasts at longer lead-times with the local detail at shorter leadtimes.

The FFC is well-positioned to further influence and benefit from future modelling advances, acting as a test-bed for evaluation of new science, and fasttracking new techniques into operational flood forecasting.

The views expressed in this paper belong to the author and do not necessarily represent the views of the author's organisation.

\section{References}

[1] Pitt, M. Learning Lessons from the 2007 Floods. 2008. Available from: http://webarchive.nationalarchives.gov.uk/20080906001345/http:/cabinet office.gov.uk/thepittreview/final_report.aspx

[2] Adams, T.E. and Pagano, T. $\overline{\mathrm{C}}$. Flood Forecasting: An International Perspective. In Flood Forecasting: A Global Perspective, eds, Adams, T. and Pagano, T. Elsevier, 2016 (in press).

[3] Roo, A.D., Thielen, J., Salamon, P., Bogner, K., Nobert, S., Cloke, H., Demeritt, D., Younis, J., Kalas, M., Bódis, K., Muraro, D., Pappenberger, F. Quality control, validation and user feedback of the European Flood Alert System (EFAS). Int J Digit Earth 2011, 4, 77-90, 2011.

[4] Alfieri, L., Burek, P., Dutra, E., Krzeminski, B., Muraro, D., Thielen, J. and Pappenberger, F. GloFAS - global ensemble streamflow forecasting and flood early warning. Hydrology and Earth System Sciences, 9, 1229312332, 2013.

[5] Price, D., Hudson, K., Boyce, G., Schellekens, J., Moore, R.J., Clark, P., Harrison, T., Connolly, E. and Pilling, C. Operational Use of a grid-based model for flood forecasting. Water Management, 165(2), 65-77, 2012.

[6] Smith, M.B., Georgakakos, K.P. and Liang, X. Special issue on the distributed model intercomparison project (DMIP). Journal of Hydrology, 298, 1-334, 2004.

[7] Best, M. J., Pryor, M., Clark, D. B., Rooney, G. G., Essery, R. L. H., Ménard, C. B., Edwards, J., Hendry, M. A., Porson, A., Gedney, N., Mercado, L. M., Sitch, S., Blyth, E., Boucher, O., Cox, P. M., Grimmond, C. S. B., and Harding, R. J.: The Joint UK Land Environment Simulator (JULES), model description - Part 1: Energy and water fluxes, Geosci. Model Dev., 4, 677-699, 2011. 
[8] Moore R.J. The probability-distributed principle and runoff production at point and basin scales. Hydrological Sciences Journal 30(2), 273-297, 1985.

[9] Cole, S. and Moore, R.J. Distributed hydrological modelling using weather radar in gauged and ungauged basins. Advances in Water Resources, 32(7), 1107-1120, 2009.

[10] Environment Agency. Understanding the performance of flood forecasting models for investment and incident management. R\&D Project Report SC130006/R2. CEH Wallingford, EA/Defra/Welsh Government/NRW Flood and Coastal Erosion Risk Management R\&D, 2015.

[11] Halcrow. Developing alerting criteria for surface water flooding, Report NA096 for the Environment Agency, Bristol, UK, 2011.

[12] Met Office. Natural Hazards Partnership, 2015. Available online: http://www.metoffice.gov.uk/nhp/hazard-impact-model.

[13] Cole, S. J., Moore, R. J., Robson, A. J., Mattingley, P. S., Black, K. B. and Kay, A. L. Evaluating G2G for use in Rapid Response Catchments: Final Report. Environment Agency, 2013.

[14] Moore R.J., Cole S.J., Bell V.A. and Jones D.A. Issues in flood forecasting: ungauged basins, extreme floods and uncertainty. Frontiers in Flood Research. 8th Kovacs Colloquium, UNESCO, Paris, eds: Tchiguirinskaia I., Thein, K.N.N. and Hubert, P., IAHS Publication 305, 103-122, 2006.

[15] Golding, B. W. Quantitative precipitation forecasting in the UK. Journal of Hydrology, 239 (1-4), 286-305, 2000.

[16] Scaife, A., Arribas, A., Blockley, E., Brookshaw, A., Clark, R., Dunstone, N., Eade, R., Fereday, D., Foland, C., Gordon, M., Hermanson, L., Knight, J., Lea, D., Maclachlan, C., Maidens, A., Martin, M., Peterson, A., Smith, D., Vellinga, M., Wallace, E., Waters, J., Williams, A. Skilful predictions of European and North American Winters. Geophysical Research Letters, 41, 2514-2519, 2014.

[17] Pilling, C. Dodds, V., Cranston, M., Price, D., Harrison, T., How, A., Victoria Dodds, Michael Cranston, David Price, Tim Harrison, Andrew How. Flood Forecasting - A National Overview for Great Britain. In Flood Forecasting: A Global Perspective, eds, Adams, T. and Pagano, T. Elsevier, 2016 (in press).

[18] Lewis, H., Mittermaier, M., Mylne, K., Norman, K., Scaife, A., Neal, R., Pierce, C., Harrison, D., Jewell, S., Kendon, M., Saunders, R., Brunet, G., Golding, B., Kitchen, M., Davies, P. and Pilling, C. From months to minutes - exploring the value of high resolution observation and prediction during the UK winter storms of 2013/14, Meteorological Applications, 2015.

[19] PAAIVQSET Diploma in Operational Hydrometeorology and Flood Forecasting (QCF), 2014, http://register.ofqual.gov.uk/Qualification /Details/601_5050_6 